\title{
Everybody Bullshits Sometimes: \\ Relationships of Bullshitting Frequency, Overconfidence and Myside Bias in the Topic of Migration
}

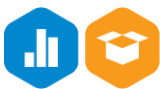

\author{
Vladimíra Čavojová (iD, Ivan Brezina \\ Institute of Experimental Psychology, Centre of Social and Psychological Sciences, Slovak Academy of Sciences, \\ Bratislava, Slovak Republic
}

\begin{abstract}
Current research on bullshit has shifted its focus from the recipient of bullshit to its producer; this trend being reflected in the new Bullshitting frequency scale (Littrell et al., 2021) measuring persuasive and evasive bullshitting. The aim of our study was to validate the scale for the Slovak population and to examine the relationship between persuasive and evasive bullshitting behavior, overconfidence and myside bias in the context of the topic of migration. Six hundred and sixty-six Slovak adults $\left(52.7 \%\right.$ men, $\left.M_{\text {age }}=41.84\right)$ participated in an online study. The two-factor structure of BFS was confirmed. The results showed that people high in persuasive bullshitting ("persuasive bullshitters"), after controlling for evasive bullshitting, felt they had more knowledge about migration, but they also showed more myside bias. Similarly, people high in evasive bullshitting ("evasive bullshitters"), after controlling for persuasive bullshitting, felt they had less knowledge about migration and tended to underestimate their knowledge. Contrary to our expectations, correlation between overconfidence and persuasive bullshitting disappeared when evasive bullshitting was controlled for, and it seems that the negative correlation was caused by evasive bullshitters being underconfident. Our results further expand the knowledge about cognitive characteristics of bullshitters and support the distinction between the two kinds of bullshitting behavior, which has implications for political debates as well.
\end{abstract}

Key words: bullshitting frequency, overconfidence, myside bias, persuasive bullshitting, evasive bullshitting

Any issue that stirs public's fear and raises heated public discussion involves a potential for spread of misinformation, often referred to as "bullshit", in social media and public discussions. There is no doubt that migration belongs among these controversial issues as it crosscuts many important domains of everyday life such as security, health, economy, and identity in its implications. As such, people who spread misinformation may be doing

Correspondence concerning this article should be addressed to Vladimíra Čavojová, Institute of Experimental Psychology, Centre of Social and Psychological Sciences, Slovak Academy of Sciences, Dúbravská cesta 9, 84104 Bratislava, Slovak Republic. E-mail: vladimira.cavojova@savba.sk

Received July 15, 2020 
so because they have a higher propensity for engaging in bullshitting, and this tendency may be influenced by cognitive biases such as overconfidence and myside bias. To examine this idea further, we decided to focus our research on those who are more likely to spread misinformation about European migration.

\section{From Bullshit Recipient to Bullshit Producer}

Before we present the rationale for our research, let us delineate what we mean by bullshitting. Frankfurt (2005) builds his definition of bullshit on Black's (1982) formal features of humbug: it is characterized by deceptive misrepresentation, is short of lying, uses pretentious words (or deeds) and is used to misrepresent person's feelings, thoughts, and attitudes. While there has been some debate about specific defining features of bullshit (Carson, 2016; Cohen, 2002; Fallis \& Stokke, 2017; Meibauer, 2016), it is generally accepted that bullshit is either a vague or obscure statement with loose attachment to the truth that aims to gain some advantage for the bullshitter (either to impress, persuade or evade an unpleasant situation).

Since the introduction of the concept of bullshit receptivity into psychological research (Pennycook et al., 2015), most of the studies have focused on the individual characteristics of bullshit recipients, such as lower analytic thinking and verbal intelligence, ontological confusion and belief in other epistemically suspect beliefs, willingness to share bullshit (Čavojová, Secară, et al., 2018), or their susceptibility to fake news and political preferences (Pennycook \& Rand, 2019; Pfattheicher \& Schindler, 2016). Bullshit receptivity was also examined in the areas of illusory pattern perception (Walker et al., 2019), abstract art (Turpin et al., 2019), science (Evans et al., 2020) and general areas of life, such as relationships, health, economics and politics (Čavojová et al., 2020).
However, all these studies focused mostly on the bullshit recipient, and so far only a few studies examined the producer of bullshit (the bullshitter). Moreover, the majority of studies focused on bullshit receptivity, relying on the Bullshit receptivity Scale (Pennycook et al., 2015), while there is a growing need for a bullshit measure related to other aspects of bullshit, as well. One of the first studies aimed at understanding the intentions of a bullshitter (Petrocelli, 2018) concluded that people, who feel pressed to express their opinion on a topic they know little about, are more likely to get involved in bullshitting. On the other hand, Petrocelli (2018) found that when there is no obligation to express an opinion, bullshitting occurs more likely if the bullshitter thinks he or she will get away with it (e.g., as a function of the perceived recipient's inability to detect bullshit). Petrocelli's approach was experimental and provided the starting point for studying the intentions of a bullshitter to bullshit, which were later examined by Littrell et al. (2021), who developed a scale measuring the frequency of and the reasons for "everyday" bullshitting. The authors conceptualized bullshitting in terms of two main factors: persuasive bullshitting and evasive bullshitting.

Persuasive bullshitting is characterized by motivation to impress and look more intelligent and/or knowledgeable than one actually is, using language to promote this imprecise impression, and using this kind of bullshitting strategy when feeling that one can easily get away with it (Littrell et al., 2021). In this way, it aligns with definitions proposed by Frankfurt (2005), Cohen (2002), Fallis and Stokke (2017) and Petrocelli (2018). On the other hand, evasive bullshitting is characterized by the desire to evade the situation, obscuring true feelings, thoughts and attitudes in order to avoid hurting oneself or others, and the bullshitter is more concerned with the truth - at 
least from the perspective of trying to conceal it, while avoiding blatant lying. This kind of bullshit aligns more with Carson's definition (2016).

The distinction between the two types of bullshitting was also verified empirically by Littrell et al. (2021), who found that the two factors correlated differently with related constructs. For example, while persuasive bullshitting (when controlled for evasive bullshitting) was positively related to overclaiming and negatively related to honesty, sincerity, impression management and cognitive ability, evasive bullshitting (when controlled for persuasive bullshitting) was significantly (and negatively) related only to sincerity and impression management (in Study 1a). Moreover, both persuasive and evasive bullshitting were positively related to relational lying and lie acceptability, but only persuasive bullshitting was positively related to antisocial lying and negatively to open-minded cognition (in Study 2). Lastly, when examining the relationship with overclaiming and lying (Study 3) with modified items, Littrell et al. (2021) found distinct pattern of correlations (when controlling for the effect of one kind of bullshitting on the other): persuasive bullshitting showed positive correlations with measures of overclaiming and telling the truth in social decision task and negative correlations with evasive response in social decision task and cognitive ability; evasive bullshitting showed negative correlations with overclaiming and positive correlations with lying and evasive response in social decision task, and no correlation with cognitive ability. Therefore, based on the described distinction between persuasive and evasive bullshitting, we expect that persuasive but not evasive bullshitting will be related to overconfidence and myside bias, which we discuss in more detail in the next section.

\section{Connecting the Dots: \\ Bullshitting, Overconfidence, and Myside Bias}

Bullshitting and overclaiming seem to be related constructs - overclaiming is defined by its authors as "the tendency to claim knowledge about nonexistent items" (Paulhus et al., 2003, p. 891), which is basically almost identical with the definition of bullshit. For some authors (Jerrim et al., 2019) these two construct are, indeed, identical and they used the false claims of knowledge of fake mathematical constructs as a measure of students' bullshitting in their PISA testing. Moreover, overclaiming is also related to overconfidence. For example, Jerrim et al. (2019) found that their teenage bullshitters expressed higher levels of self-confidence in their skills than non-bullshitters, even when controlled for academic ability, and that they reported significantly more "socially desirable" strategies when solving problems. Despite the fact that their measure of bullshitting is a measure of overclaiming, similar results were observed also in other studies. Pennycook and Rand (2019) found that people who claimed more fake knowledge tended also to perceive fake news as more accurate and that overclaiming was related to bullshit receptivity. Persuasive evidence of a relationship between overclaiming and overconfidence was also brought by the study of Atir et al. (2015), who found that self-perceived expertise in various domains positively predicted claiming of non-existing knowledge within various domains (biology, finance, geography) independently of actual knowledge.

Overconfidence and overclaiming can represent impression management strategies. Bensch et al. (2019) examined overclaiming, overconfidence, and socially desirable responding as manifestation of a general posi- 
tivity bias, i.e. attempt to tap a positive distortion in self-reports. They identified three factors underlying different measures of positivity bias (denying common faults, self-deceptive enhancement, and claiming unlikely virtues), but overclaiming and overconfidence did not load on any of the three factors, indicating that these measures have more specific than shared variance. However, the two identified second-order factors self-deceptive enhancement and claiming unlikely virtues are reminiscent of persuasive bullshitting and they showed positive correlation with overconfidence. Anderson et al. (2012) focused on another motive for overconfident behavior than impression management: enhancement of person's social status. Their results indicate that status motive does, indeed, promote overconfidence, that overconfidence leads to behavior that makes people appear more competent to others and that it can actually help them achieve higher status.

Overclaiming and overconfidence have implications for political behavior as well. For example, recent study showed that overclaiming together with overconfidence (increased self-perceived understanding yet decreased actual knowledge) predicted an anti-establishment vote (van Prooijen \& Krouwel, 2020). Moreover, other studies showed that overconfidence can influence political reasoning (Motta et al., 2018), that the strength of political partisanship and ideological extremeness can be predicted by overconfidence in one's beliefs (Ortoleva \& Snowberg, 2015a, 2015b), and that priming partisanship can lead to overconfidence especially in the least knowledgeable participants (Anson, 2018). Similarly, Druckman (2004) found that those people who are the most susceptible to contextual influence (such as the framing effect) on their political preference are, at the same time, most confident in their judgment, thus showing overconfidence. Similarly, Bašnáková and Valuš (2019) found that participants greatly overestimated their knowledge about the topic of migration (they found no correlation between objective and subjective knowledge), but the subjective feeling of competence together with close-mindedness were the strongest predictors of perceived risks and fear associated with refugees. Moreover, personal values such as racism and conservativism added $17.4 \%$ for perceived risk and $17.6 \%$ for perceived fear of additional explained variance to the model.

Based on these findings, we have reason to believe that not only will persuasive (but not evasive) bullshitting be associated with overconfidence, but also that overconfidence and bullshitting is connected to myside bias in reasoning, as should be evidenced in such polarizing issue as migration.

Myside bias occurs when people evaluate, generate, and test evidence in a manner that is biased toward their prior attitudes and opinions and concerns reasoning biased toward personal opinions or stances (Macpherson \& Stanovich, 2007). Myside bias has been studied mainly by having people evaluate arguments about various controversial topics (e.g., abortion) and it was consistently shown that people tend to give more arguments supporting the attitude they favor than against the opposing attitude (Baron, 1995; Stanovich \& West, 1997, 1998, 2008), and the same results were found in studies using more formalized evaluation of syllogisms (Čavojová, Šrol, et al., 2018; Thompson \& Evans, 2012).

Although it is clear that myside bias would apply to politics as well, there is surprisingly little research directly addressing this issue apart from the large amount of evidence provided by Lodge and Taber (2013) on people's decisions about political issues driven by their prior emotions related to respective issues. Moreover, stronger feelings can lead to more polarization and strength of partisanship (Clifford, 2019; Tappin \& McKay, 2019). 
Based on the previous review, we expect that people with stronger attitudes toward migration will show stronger myside bias, and as overconfidence increased the strength of beliefs (Ortoleva \& Snowberg, 2015a, 2015b), then people who are more overconfident and have strong attitudes will show the strongest myside bias. Similarly, because people who admit to more persuasive bullshitting are less concerned with the truth and tend to exaggerate, they should care less about whether the arguments for their preferred position are based on facts, and again, show stronger myside bias.

\section{Aims of the Current Study}

The aims of the current study were, therefore, threefold. First, we aimed to examine the psychometric properties of the new BFS on the sample of Slovak participants. As the instrument relies on self-reporting, cultural differences in response style may represent a factor, especially when it comes to acknowledging types of evasive or unflattering behaviors, which the scale was designed to measure. Our secondary goal was to expand the research on frequency of bullshitting to the area of overconfidence and myside bias - Littrell et al. (2021) related BFS to overclaiming in politics, and we decided to take it a step further. We choose to examine myside bias and overconfidence in the topic of migration to increase the ecological validity of the task. We expect that persuasive bullshitting (but not evasive bullshitting) will correlate positively with overconfidence and myside bias. Moreover, we expect to observe stronger myside bias in people who are more overconfident and who bullshit more. Lastly, as the topic of bullshitting represents relatively new and uncharted territory in psychological research, our final and exploratory goal was to examine the role of gender, age, and education in relation to the above-mentioned variables.

\section{Methods}

\section{Participants}

The representative sample comprised 666 Slovak nationals ( $52.7 \%$ were men) aged between 19 and $84(M=41.84, S D=13.90)$. Of these, $30.2 \%$ had completed lower secondary education, $45.5 \%$ had attained upper secondary education and $24.4 \%$ had completed higher education. The participants were recruited by an external participant recruitment agency, which complies with the ESOMAR international code, and they were rewarded with points (within the remuneration system of the external agency), which can be exchanged for various products. All the data were collected online.

\section{Materials}

All reported materials and data are publicly available at: https://osf.io/4hvmu/.

At the beginning of the survey, after signing an informed consent, participants were asked to indicate their basic demographic variables, such as gender, age, education. It also served as a quota variable for the external agency.

Bullshitting frequency was measured by the Bullshitting Frequency Scale (BFS) (Littrell et al., 2021), which is a newly developed scale designed to capture the frequency with which individuals engage in bullshitting in everyday situations. We used the version from Study 1 containing 12 items; participants indicate on a 5 -point scale ( $1=$ never, $5=$ all the time $)$ how often they embellish or exaggerate their behavior in various situations and for various reasons. Eight items are designed to measure persuasive bullshitting, while 4 items are designed to measure evasive bullshitting (the exact wording of all items is in Table 1). The authors of the BFS confirmed the two-factor structure of the scale. 
Attitudes toward migration. Participants were asked to indicate their level of agreement with eight statements (e.g., "Migration can effectively solve the problem of the aging of the European population.") on a scale from 1 (totally disagree) to 7 (totally agree). All items were recoded so that higher scores indicated more positive attitudes toward migration, while lower scores indicated a negative attitude toward migration. The scale measures attitudes toward economic migrants as well as refugees, so before creating a total mean score, we carried out a reliability analysis and a factor analysis. Internal consistency of the scale was good (Cronbach's $\alpha=.845$ ) and all items loaded into one single factor.

Subjective competence in the topic of $\mathrm{mi}$ gration was measured by a single question: Please rate your knowledge about migration on the scale from 1 = "I don't understand this issue at all" to $10=$ "I understand the issue completely".

Actual knowledge in the topic of migration was measured by 10 single-choice questions about migration (e.g., "Which country has the largest proportion of migrants to its own population?" Answers: USA, Spain, Qatar, Germany, Lebanon, Uganda). Each correct answer received 1 point and we used the sum of correct answers as the total score of actual knowledge.

Overconfidence was operationalized as overestimation (i.e., specific type of overconfidence, Moore \& Healy, 2008) and was measured by a single question after completing the knowledge quiz: "You have just completed the quiz with 10 questions. Please, estimate the number of your correct answers." Overestimation was calculated by subtracting the actual number of correct answers from the estimated number of correct answers. A positive number indicates overconfidence (higher estimated than the actual number of correct answers), while a negative number indicates underconfidence (higher actual than the es- timated number of correct answers); at the same time, it indicates the magnitude of over/underestimation.

Myside bias. We asked participants to evaluate six arguments related to migration and multiculturalism (e.g., "While the concept of multi-culturalism was not equally successful in all countries, we can learn from what works and draw upon the more positive aspects of migration.") using the scale of factfulness (the presented argument was based on facts that are easy to check) ranging from 0 (totally disagree) to 10 (totally agree). Arguments were constructed in such a way that half of them argued for positives of multiculturalism and the other half argued for negatives of multiculturalism. First, we calculated the average for the scale of factfulness, separately for pro and con arguments. Then we calculated the myside bias index by subtracting the scores for con arguments from the scores of pro arguments (Čavojová, Šrol, et al., 2018). Thus, positive scores reflect the higher evaluation of factfulness of positive arguments (for multiculturalism), while negative scores reflect the higher evaluation of factfulness of negative arguments (against multiculturalism).

Participants also elaborated upon arguments in a task, which is part of a separate study and is not reported here. Means, standard deviations, Cronbach's alphas are presented in Table 2.

\section{Results}

Verifying Psychometric Properties of the Bullshitting Frequency Scale

First, we sought to confirm whether a one-factor or a two-factor structure is the better fit for the data by conducting a confirmatory factor analysis (CFA) using JASP. Results suggested that the two-factor model $\left(\chi^{2}(53)=164.74, p<.001 ; C F I=.98\right.$; 
$\mathrm{TLI}=.97 ;$ RMSEA $=.06$ ) is a better fit for the data compared to a one-factor model $\left(\chi^{2}(54)=278.21, p<.001 ; \mathrm{CFI}=.95 ; \mathrm{TLI}=.94\right.$; RMSEA $=.08)$. In Table 1 we provide mean, standard deviations and factor loadings for the scale items. These results corroborate the findings of Littrell et al. (2021), factors are composed by the same items, and both persuasive and evasive bullshitting factors account for similar variance even in a different cultural setting.
Relationships between Bullshitting, Overconfidence, and Myside Bias

Next, we set to examine the correlations between bullshitting and overconfidence. From the results in Table 2 we can see negative correlations between persuasive $(r=-.10, p=$ $.008)$, evasive $(r=-.14, p<.001)$ bullshitting and overconfidence. It means that there is a slight tendency for people who admit engag-

Table 1 Mean, standard deviations and factor loadings for each scale item

\begin{tabular}{|c|c|c|c|c|c|c|c|c|}
\hline & Indicator & $M$ & $S D$ & Estimate & $S E$ & $Z$ & $p$ & $B$ \\
\hline \multirow[t]{8}{*}{ BFS-p } & $\begin{array}{l}\text { By pretending to know more } \\
\text { about a topic than I actually do }\end{array}$ & 2.84 & 1.53 & 1.15 & 0.05 & 22.5 & $<.001$ & 0.76 \\
\hline & $\begin{array}{l}\text { When I want the thing(s) I'm } \\
\text { talking about to sound more } \\
\text { interesting or exciting }\end{array}$ & 3.21 & 1.67 & 1.34 & 0.05 & 24.7 & $<.001$ & 0.80 \\
\hline & $\begin{array}{l}\text { When I know it will be easy to get } \\
\text { away with it }\end{array}$ & 3.00 & 1.57 & 1.24 & 0.05 & 23.9 & $<.001$ & 0.79 \\
\hline & $\begin{array}{l}\text { When I want to impress the } \\
\text { people I'm talking to }\end{array}$ & 3.15 & 1.65 & 1.34 & 0.05 & 25.1 & $<.001$ & 0.81 \\
\hline & $\begin{array}{l}\text { When I want others to see me as } \\
\text { more intelligent or knowledgeable }\end{array}$ & 2.75 & 1.54 & 1.25 & 0.05 & 24.9 & $<.001$ & 0.81 \\
\hline & $\begin{array}{l}\text { When I want to contribute to a } \\
\text { conversation or discussion even } \\
\text { though I'm not well-informed on } \\
\text { the topic }\end{array}$ & 2.71 & 1.53 & 1.11 & 0.05 & 21.4 & $<.001$ & 0.73 \\
\hline & $\begin{array}{l}\text { When I know it will help me } \\
\text { achieve a goal }\end{array}$ & 3.44 & 1.67 & 1.19 & 0.05 & 20.9 & $<.001$ & 0.72 \\
\hline & $\begin{array}{l}\text { When I'm trying to fit in better or } \\
\text { be more accepted by the person } \\
\text { or people I'm interacting with }\end{array}$ & 2.90 & 1.58 & 1.32 & 0.05 & 26.3 & $<.001$ & 0.84 \\
\hline \multirow[t]{4}{*}{ BFS-e } & $\begin{array}{l}\text { When someone asks me } \\
\text { something that I want to avoid } \\
\text { giving a direct answer to }\end{array}$ & 3.27 & 1.56 & 1.16 & 0.05 & 21.2 & $<.001$ & 0.75 \\
\hline & $\begin{array}{l}\text { When I need to fake/bluff my way } \\
\text { out of a conversation or situation }\end{array}$ & 3.38 & 1.62 & 1.24 & 0.06 & 22.1 & $<.001$ & 0.77 \\
\hline & $\begin{array}{l}\text { When being fully honest would be } \\
\text { harmful or embarrassing to me or } \\
\text { someone else }\end{array}$ & 3.84 & 1.69 & 1.12 & 0.06 & 18.2 & $<.001$ & 0.66 \\
\hline & $\begin{array}{l}\text { When I don't want to tell someone } \\
\text { what I really think }\end{array}$ & 3.26 & 1.69 & 1.18 & 0.06 & 19.4 & $<.001$ & 0.70 \\
\hline
\end{tabular}


ing in bullshitting behavior to underestimate rather than overestimate their knowledge.

We were also interested in the relationship between bullshitting and myside bias. As we designed arguments that were balanced in their support or disapproval of multiculturalism (as a positive effect of migration) and neither side relied heavily on facts, it could be expected that participants evaluate pro and con arguments as equally based on facts, if their responding was not influenced by their prior attitudes. Calculation of myside bias index and the subsequent analyses were based on the approach by Čavojová et al. (2018). It suggests that by subtracting the evaluations of con arguments from those of the pro arguments, we get a clear measure of the extent to which participants' responding was affected by the content of the argument e.g., whether participants evaluated con arguments as more factful than pro arguments. In the whole sample, the mean of the myside bias index was quite skewed to a more favorable evaluation of anti-migration arguments $(M=-1.22, S D=3.25)$.
Next, we explored correlations among the myside bias index and its potential predictors. As can be seen from Table 2, myside bias index was strongly and positively correlated with pro-migration attitudes $(r=.56$, $p<.001$ ). This correlation suggests that people with stronger pro-immigration attitudes evaluated arguments promoting multiculturality as more based on facts than arguments against multiculturality, which is exactly the pattern of results that would be expected based on myside bias. There was a weak positive correlation with knowledge $(r=.08, p=$ $.048)$ and negative correlation with overconfidence $(r=-.15, p<.001)$, suggesting that people scoring higher in objective knowledge evaluated pro-multiculturalism arguments as more based on facts, while people who overestimated themselves tended to evaluate anti-multiculturalism arguments as more based on facts.

Because Littrell et al. (2021) recommend using partial correlations controlling for each subscale separately due to possible suppression effect, we also examined partial correla-

Table 2 Descriptive and correlational data for all study variables with BSF, BSF-persuasive, and BSFevasive

\begin{tabular}{|c|c|c|c|c|c|c|c|c|c|c|c|}
\hline & \multicolumn{7}{|c|}{ Bivariate } & \multicolumn{4}{|c|}{ Partial } \\
\hline & $M$ & $S D$ & $\alpha$ & 1. & 2. & 3. & 4. & 5. & 6. & BFS-p & BFS-e \\
\hline 1. BFS-persuasive & 3.00 & 1.29 & .93 & 1 & & & & & & & \\
\hline 2. BFS-evasive & 3.44 & 1.31 & .81 & .76 & 1 & & & & & & \\
\hline 3. Attitudes & 2.87 & 1.9 & .85 & .12 & .12 & 1 & & & & .03 & .06 \\
\hline 4. Subjective competence & 6.40 & 2.6 & - & -.04 & -.14 & .03 & 1 & & & .11 & -.17 \\
\hline 5. Knowledge & 3.32 & 1.46 & .36 & .08 & .05 & .13 & .11 & 1 & & .05 & -.01 \\
\hline 6. Overconfidence & 2.11 & 2.22 & - & -.10 & -.14 & -.15 & .20 & -.62 & 1 & .01 & -.10 \\
\hline 7. Factfulness index ${ }^{1}$ & -1.22 & 3.25 & - & .15 & .12 & .56 & -.01 & .08 & -.15 & .10 & .00 \\
\hline
\end{tabular}

Note. Correlations are based on 666 observations. All correlations above $r=.08$ are significant at $p<$ .05 , above $r=.10$ are significant at $p<.01$, and above $r=.12$ are significant at $p<.001$. Significant correlations are presented in italics $(p<.05)$. BSF- $p=$ Persuasive bullshitting, controlling for evasive; BSF-e = Evasive bullshitting, controlling for persuasive.

$1=$ Positive score indicates that positive arguments about multiculturalism were evaluated as more based on facts, while negative score indicates that negative arguments about multiculturalism were evaluated as more based on facts. 
tions of persuasive and evasive bullshitting. Interestingly, the correlation with attitudes disappeared. Persuasive bullshitting (controlled for evasive bullshitting) correlated positively with subjective competence $(r=.11, p=.005)$ and myside bias $(r=.10, p=.014)$, but there was no correlation with overconfidence ( $r=$ $.001, p=.820)$. On the other hand, evasive bullshitting (controlled for persuasive bullshitting) now correlated negatively with subjective competence $(r=-.17, p<.001)$ and overconfidence $(r=-.10, p=.010)$, but there was no correlation with myside bias $(r=.00$, $p=.914)$. In other words, people who scored higher in persuasive bullshitting perceived themselves as more knowledgeable in the

Table 3a Simple moderation analysis of attitudes as predictor of myside bias index and overconfidence as a moderator

\begin{tabular}{lcccc}
\hline Model & $b[95 \% \mathrm{Cl}]$ & $s e$ & $t$ & $p$ \\
\hline Constant & $-1.22[-1.43 ;-1.02]$ & 0.11 & -11.59 & $<.001$ \\
Attitudes & $1.63[1.44 ; 1.82]$ & 0.10 & 16.85 & $<.001$ \\
Overconfidence & $-0.10[-0.20 ;-0.01]$ & 0.05 & -2.13 & .03 \\
Attitudes x Overconfidence & $-0.02[-0.11 ; 0.06]$ & 0.04 & -0.52 & .60 \\
\hline
\end{tabular}

Model: $R^{2}=.32, F(3,662)=102.07, p<.001$; Change: $\Delta R^{2}=.00, F(1,662)=0.27, p=.60$

Note. $N=666$. The table contains unstandardized coefficients (b's) with their corresponding $95 \%$ confidence intervals, standard errors, $t$-values and levels of significance. $\Delta R^{2}$ denotes $\mathrm{R}$-squared change due to interaction (adding moderator to the regression). Variables were mean centered before the analysis.

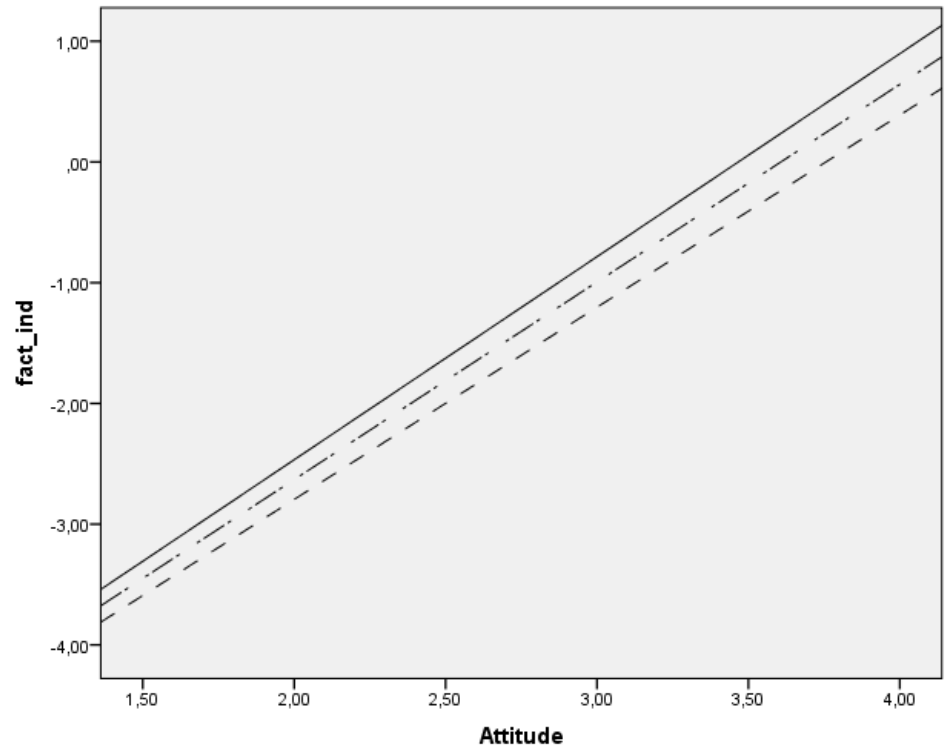

Figure 1 Attitudes as a predictor of factfulness index at low (full line), mean (dash-dotted line), and high (dashed line) levels of overestimation. 
topic of migration than people scoring lower in persuasive bullshitting and they judged arguments for migration as more based on truth. In contrast, people scoring high in evasive bullshitting perceived themselves as less knowledgeable than people scoring lower on evasive bullshitting and they were less overconfident.

Next, we examined whether people who are more overconfident and who bullshit more would show stronger myside bias. For this purpose, we performed three simple moderation

Table 3b Simple moderation analysis of attitudes as predictor of myside bias index and persuasive bullshitting as a moderator

\begin{tabular}{lccrr}
\hline Model & $b[95 \% \mathrm{Cl}]$ & $s e$ & \multicolumn{1}{c}{$t$} & \multicolumn{1}{c}{$p$} \\
\hline Constant & $-1.18[-1.39 ;-0.98]$ & 0.10 & -11.35 & $<.001$ \\
Attitudes & $1.59[1.406 ; 1.78]$ & 0.10 & 16.44 & $<.001$ \\
Persuasive bullshitting & $0.20[0.05 ; 0.36]$ & 0.08 & 2.52 & .012 \\
Attitudes x persuasive bullshitting & $-0.21[-0.35 ;-0.06]$ & 0.07 & -2.82 & .005 \\
\hline
\end{tabular}

Model: $R^{2}=.33, F(3,662)=107.23, p<.001$; Change: $\Delta R^{2}=.01, F(1,662)=7.93, p=.005$

Note. $N=666$. The table contains unstandardized coefficients (b's) with their corresponding $95 \%$ confidence intervals, standard errors, $t$-values and levels of significance. $\Delta R^{2}$ denotes $\mathrm{R}$-squared change due to interaction (adding moderator to the regression). Variables were mean centered before the analysis.

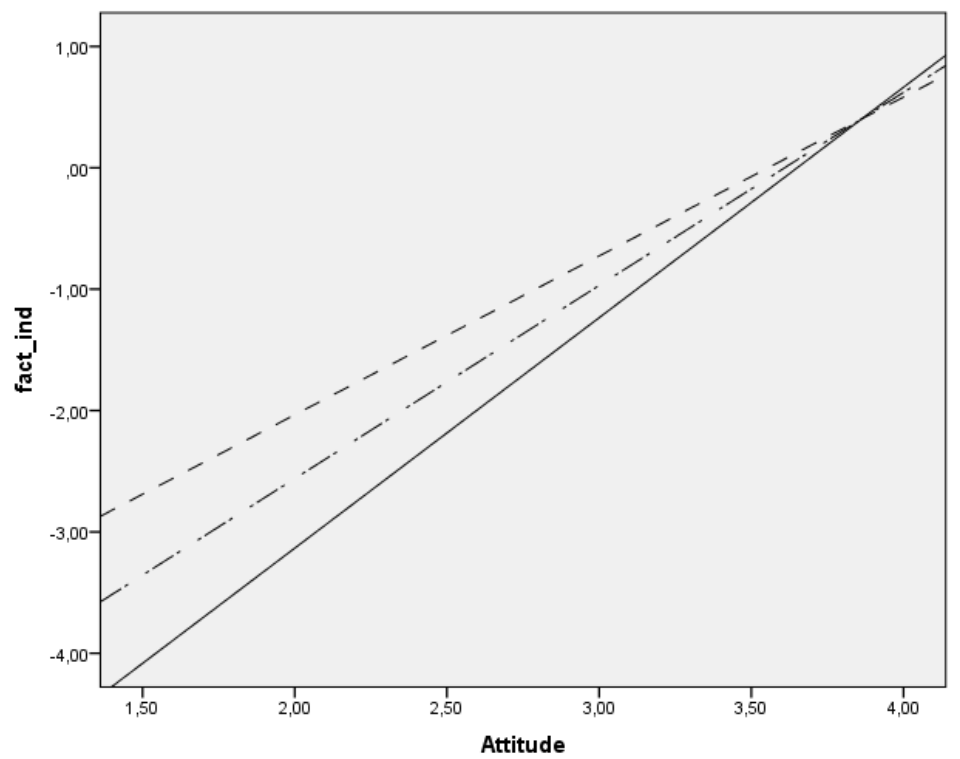

Figure 2 Attitudes as a predictor of factfulness index at low (full line), mean (dash-dotted line), and high (dashed line) levels of persuasive bullshitting. 
analyses (Table 3a, 3b, 3c), in which attitudes were used as predictor $(X)$ of the scores on myside bias index $(\mathrm{Y})$ with overconfidence, persuasive bullshitting, and evasive bullshitting as moderators (M). All moderation analyses were conducted with Hayes' (2013) macro (Model
1) implemented in the IBM SPSS v.22 software.

We can see that overconfidence is a predictor of myside bias index, but there is not a significant interaction with attitudes (Table 3a, Figure 1). Persuasive bullshitting, but not

Table 3c Simple moderation analysis of attitudes as predictor of myside bias index and evasive bullshitting as a moderator

\begin{tabular}{lccrr}
\hline Model & $b[95 \% \mathrm{Cl}]$ & $s e$ & $t$ & $p$ \\
\hline Constant & $-1.18[-1.39 ;-0.97]$ & 0.10 & -11.26 & $<.001$ \\
Attitudes & $1.60[1.41 ; 1.80]$ & 0.10 & 16.53 & $<.001$ \\
Evasive bullshitting & $0.10[-0.06 ; 0.26]$ & 0.08 & 1.24 & .217 \\
Attitudes x evasive bullshitting & $-0.21[-0.35 ;-0.07]$ & 0.07 & -2.93 & .004 \\
\hline
\end{tabular}

Model: $R^{2}=.32, F(3,662)=105.05, p<.001 ;$ Change: $\Delta R^{2}=.01, F(1,662)=8.58, p=.004$

Note. $N=666$. The table contains unstandardized coefficients (b's) with their corresponding $95 \%$ confidence intervals, standard errors, $t$-values and levels of significance. $\Delta R^{2}$ denotes $\mathrm{R}$-squared change due to interaction (adding moderator to the regression). Variables were mean centered before the analysis.

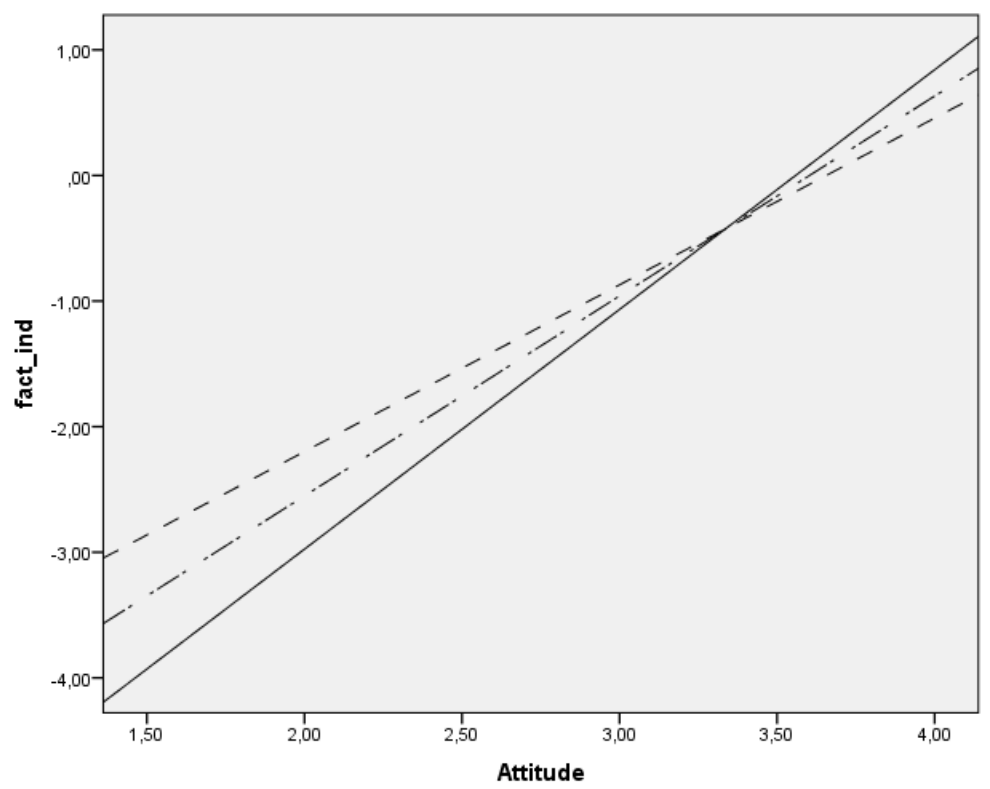

Figure 3 Attitudes as a predictor of factfulness index at low (full line), mean (dash-dotted line), and high (dashed line) levels of evasive bullshitting. 
evasive bullshitting, is a positive predictor of myside bias index, while their interaction with attitudes is negative (Figures 2 and 3 ). To summarize, whether someone shows myside bias depends mostly on their attitudes - people with pro-migration attitudes evaluated pro-migration arguments as more trustworthy in comparison with people with anti-migration attitudes, and vice versa. Also, people who bullshit more show higher myside bias index, but they have smaller effect of attitudes on myside bias index.

Exploration of the Relationship between Demographic Variables and Bullshitting

Lastly, we explored gender, age, and education differences. We examined the differences between men and women by $t$-tests and the results are summarized in Table 4.
Although there were no significant differences between men and women in general bullshitting frequency and frequency of persuasive bullshitting, women admitted significantly more to evasive bullshitting. There were no differences between men and women in their attitudes toward migration and evaluation of truthfulness of arguments related to multiculturalism. Men felt significantly more knowledgeable in the topic of migration and it seems rightly so, as they also had significantly more knowledge. Men and women did not differ in the overconfidence in their knowledge.

Lastly, we examined correlations between age and education and all the studied variables (Table 5).

The results suggest that there is a slight tendency for older people to bullshit less, especially in regards to the persuasive form of bullshitting.

Table 4 Differences between men and women in the observed variables

\begin{tabular}{|c|c|c|c|c|c|c|c|}
\hline & \multicolumn{2}{|c|}{$\operatorname{men}(N=351)$} & \multicolumn{2}{|c|}{ women $(N=314)$} & \multirow[b]{2}{*}{$t$} & \multirow[b]{2}{*}{$p$} & \multirow[b]{2}{*}{$d$} \\
\hline & $M$ & $S D$ & $M$ & $S D$ & & & \\
\hline 1. BFS & 3.11 & 1.20 & 3.19 & 1.25 & -0.90 & .367 & 0.065 \\
\hline 2. BFS-persuasive & 3.00 & 1.26 & 3.01 & 1.32 & -0.13 & .896 & 0.008 \\
\hline 3. BFS-evasive & 3.33 & 1.25 & 3.56 & 1.35 & -2.29 & .022 & 0.177 \\
\hline 4. Attitudes & 2.90 & 1.13 & 2.83 & 1.05 & 0.83 & .410 & -0.064 \\
\hline 5. Subjective competence & 6.66 & 1.98 & 6.11 & 2.12 & 3.40 & .001 & -0.269 \\
\hline 6. Knowledge & 3.59 & 1.55 & 3.02 & 1.29 & 5.17 & $<.001$ & -0.398 \\
\hline 7. Overconfidence & 2.14 & 2.21 & 2.05 & 2.21 & 0.52 & .606 & -0.041 \\
\hline
\end{tabular}

Note. Significantly higher scores are marked in italics $(p<.05)$.

Table 5 Correlations between age and education and the variables in the study

\begin{tabular}{|c|c|c|c|c|c|c|c|}
\hline & BFS & $\begin{array}{c}\text { BFS- } \\
\text { persuasive }\end{array}$ & $\begin{array}{c}\text { BFS- } \\
\text { evasive }\end{array}$ & Attitudes & $\begin{array}{c}\text { Subj. } \\
\text { competence }\end{array}$ & Knowledge & Overconfidence \\
\hline Age & -.08 & -.08 & -.06 & .05 & .13 & .09 & .08 \\
\hline Education & -.01 & -.00 & -.01 & .21 & .12 & .19 & -.10 \\
\hline
\end{tabular}

Note. All correlations $\geq .08$ are significant at $p<.05$. Significant correlations are marked in italics. 
Older people also rated their knowledge significantly higher, knew more about migration, slightly overestimated themselves more, and evaluated pro-multiculturalism as more based on facts. Except for relations to bullshitting, the same was also true for people with higher education.

\section{Discussion}

For the current study, we used a new Bullshitting Frequency Scale (Littrell et al., 2021) which has greatly enhanced our understanding of the processes behind susceptibility to pseudo-profound or otherwise misleading information. However, the bulk of this research attention has focused on cognitive and dispositional factors related to bullshit (the product, which showed excellent psychometric properties. The same two-factor structure described by the authors of the scale was replicated in our study. However, our main aim was to expand the research of frequency of bullshitting to the area of overconfidence and myside bias. The results showed that people who admitted they engage in persuasive bullshitting ("persuasive bullshitters"), after controlling for evasive bullshitting, felt they had more knowledge about migration, but they showed also more myside bias. Similarly, people who admitted they engage in evasive bullshitting ("evasive bullshitters"), after controlling for persuasive bullshitting, felt they had less knowledge about migration and tended to underestimate their knowledge. Contrary to our expectations, correlation between overconfidence and persuasive bullshitting disappeared when evasive bullshitting was controlled for and it seems that the negative correlation was caused by evasive bullshitters being underconfident. Nevertheless, these results further corroborate the distinction between persuasive and evasive bullshitting made by Littrell et al. (2021) - even though our results suggest that it is not overconfidence that drives people to pretend to know more than they actually do or look more knowledgeable (persuasive bullshitting). On the other hand, underestimation of one's knowledge does seem to lead to a tendency to bullshit one's way out of a situation (evasive bullshitting). Yet, most of the correlations remain weak, suggesting more research on the studied relations rather than conclusions should be made at this stage.

Although, we confirmed myside bias in the topic of migration - i.e., attitudes were the strongest predictor of evaluation of arguments - our expectation to find a stronger myside bias in people who are more overconfident was not observed. On the other hand, persuasive bullshitting predicted myside bias and the interaction with attitudes was also significant. The stronger the attitudes, the stronger the myside bias, but the effect of attitudes was moderated by persuasive bullshitting, suggesting that the effect of attitudes on un/favorable evaluation of the arguments regarding multiculturalism was smaller for people high in persuasive bullshitting.

The negative relationship between reported persuasive bullshitting and overconfidence disappeared when evasive bullshitting was controlled for, and only negative correlation between overconfidence and evasive bullshitting (when controlled for persuasive bullshitting) remained significant. Results also showed that people with pro-migration attitudes were generally more knowledgeable about the topic and interestingly, subjective competence correlated not only with overconfidence (which is expected) but also with actual knowledge (which is unexpected, as according to the Dunning-Kruger effect the most incompetent individuals tend to view themselves as more competent than they are). It could suggest that people, who are better at realizing that they do not know 
something, are also better at realizing that they are bullshitting (i.e., they are aware that they pretend to know more than they actually do), and therefore, they were able to give us more honest answers than people who do not realize the gap in their knowledge and who are not aware of the fact that they actually engage in bullshitting behavior (metacognitive deficit).

It is also possible that the self-reported measure, despite its more than satisfactory psychometric properties, is a mere approximation to the measurement of bullshitting behavior, as it relies not only on the willingness of people to tell the truth but also on their metacognition. Extensive research showed that people are not very good at judging their abilities or recognizing the contextual effects on their reasoning (Wilson, 2002). The more knowledgeable people are the more likely they are to underestimate themselves because they are more aware of the gaps in their knowledge, therefore, they may give honest answers about their bullshitting. However, whether those who are not aware of their bullshitting are, in fact, bullshitting even more is a legitimate, though unanswerable question, acknowledged by the authors of the BFS scale as well (Littrell et al., 2021).

Our results also supported previous findings of myside bias in the realm of migration and multiculturalism. Similarly, as other studies (Baron, 1995; Čavojová, Šrol, et al., 2018; Klaczynski, 2000; Stanovich \& West, 2007; Toplak \& Stanovich, 2003), we found evidence that people evaluated more favorably arguments that were in line with their prior position, and they displayed stronger myside bias the stronger their attitudes about migration were. We also expanded the research on myside bias by showing that persuasive bullshitting predicts myside bias, even though its effect is quite small, and prior attitudes remain the strongest factor. Interestingly, people displayed strong myside bias in favor of their attitude irrespective of their actual knowledge about the issue. When analyzing myside bias according to the knowledge quartile, we found that participants in the lowest knowledge quartile displayed the strongest myside bias $(M=-1.80, S D=3.15)$ and they differed significantly from the participants in the highest quartile $(M=-0.68, S D=3.59$, $\left.t_{(275)}=-2.75, p=.006\right)$, which could be attributed to Dunning-Kruger effect.

We also explored differences in bullshitting behavior depending on gender, age, and education. We found that men and women differed only in the amount of evasive bullshitting, with significantly more women admitting that they bullshit when they want to fake/bluff their way out of a conversation or situation or when they want to avoid the embarrassment of themselves or others. This is in line with the findings of Erat and Gneezy (2012), who found that women were more likely to tell altruistic white lies than men, although they are generally less likely to lie when it is costly to the other side. On the other hand, Jerrim et al. (2019) found in their study that boys are much more likely to be bullshitters than girls, but this difference can be caused by the age of their sample (teenagers), as we also found slight tendency for older people to bullshit less. Another reason can be their conceptualization of bullshitting (which was basically measured as overclaiming). Also, there was no effect of education on bullshitting behavior, suggesting that both highly and less educated people use these persuasive and evasive bullshitting strategies.

The main limitation of our study is the self-reported nature of the bullshitting frequency scale and in further research, we would like to measure bullshitting behavior more directly using behavioral measures. On the other hand, devising behavior measures of bullshitting poses different challenges - 
for example, how to judge what is bullshit and what is not without knowing the actual intentions of the person, especially given the suspicion that people might not be aware of their true intentions (Newell \& Shanks, 2014; Wilson, 2002). Therefore, until we have such a measure, self-report scales on bullshitting may help us understand the complicated phenomenon of bullshitting. It would be also necessary to explore and understand the relationship between both persuasive and evasive bullshitting and bullshit receptivity; either in the context of pseudo-profound bullshit, or a general one (Čavojová et al., 2020). The main strength of the Bullshitting Frequency Scale, however, is the distinction between persuasive and evasive bullshitting, which showed a different pattern of relationships in our study as well, and stressed the need for the distinction between these two types of bullshitting.

To conclude, we believe our aims, as well as the findings of our study, open an interesting direction for further research. Investigating bullshit in a combination of 1) self-reported frequency, 2) bullshit receptivity, as well as 3) one's production may offer valuable insight into the topic in the future. Together with variables of often studied and well-documented cognitive failures, such as myside bias or confirmation bias, it captures some of the most relevant "landmarks of the territory" of human errors in information processing and communication. Lastly, we are convinced that implementing such research into the context of the topic that resonates in the general public - migration in the case of our study - increases the interest of the participants, and helps to elevate the research from laboratory tasks to real-life problems.

\section{Acknowledgement}

The study was supported by the Slovak Research and Development Agency as part of the research project APVV-16-0153: "Cognitive failures - individual predictors and intervention possibilities" and VEGA 2/0053/21: "Examining unfounded beliefs about controversial social issues". The authors would like to thank Mgr. Michal Kohút, PhD. for the help with designing the questionnaire as well as his valuable comments and statistical insights on the earlier drafts of the manuscript.

\section{Authors' ORCID \\ Vladimíra Čavojová \\ https://orcid.org/0000-0002-7295-8803 \\ Ivan Brezina \\ https://orcid.org/0000-0002-8158-7805}

\section{References}

Anderson, C., Brion, S., Moore, D. A., \& Kennedy, J. A. (2012). A status-enhancement account of overconfidence. Journal of Personality and Social Psychology, 103(4), 718-735. https://doi. org/10.1037/a0029395

Anson, I. G. (2018). Partisanship, political knowledge, and the Dunning-Kruger effect. Political Psychology, 39(5), 1173-1192. https://doi.org/10.1111/ pops.12490

Atir, S., Rosenzweig, E., \& Dunning, D. (2015). When knowledge knows no bounds: Self-perceived expertise predicts claims of impossible knowledge. Psychological Science, 26(8), 1295-1303. https://doi.org/10.1177/0956797615588195

Baron, J. (1995). Myside bias in thinking about abortion. Thinking \& Reasoning, 1(3), 221-235. https://doi.org/10.1080/13546789508256909

Bašnáková, J., \& Valuš, L. (2019). What are they afraid of? Cognitive predictors of risk assessment related to refugees. Cognition and Artificial Life / Kognícia a Umelý Život 2019, 1-2. http://cogsci. fmph.uniba.sk/kuz2019/files/zbornik/basnakova-valus.pdf

Bensch, D., Paulhus, D. L., Stankov, L., \& Ziegler, M. (2019). Teasing apart overclaiming, overconfidence, and socially desirable responding. Assessment, 26(3), 351-363. https://doi. org/10.1177/1073191117700268 
Black, M. (1982). The prevalence of humbug. Philosophic Exchange, 13(1). http://digitalcommons. brockport.edu/phil ex/vol13/iss1/4

Carson, T. L. (2016). Frankfurt and Cohen on bullshit, bullshiting, deception, lying, and concern with the truth of what one says. Pragmatics \& Cognition, 23(1), 53-67. https://doi. org/10.1075/pc.23.1.03car

Čavojová, V., Brezina, I., \& Jurkovič, M. (2020). Expanding the bullshit research out of pseudotranscendental domain. Current Psychology. https://doi.org/10.1007/s12144-020-00617-3

Čavojová, V., Secară, E. C., Jurkovič, M., \& Šrol, J. (2018). Reception and willingness to share pseudo-profound bullshit and their relation to other epistemically suspect beliefs and cognitive ability in Slovakia and Romania. Applied Cognitive Psychology, 1-13. https://doi.org/10.1002/ acp.3486

Čavojová, V., Šrol, J., \& Adamus, M. (2018). My point is valid, yours is not: Myside bias in reasoning about abortion. Journal of Cognitive Psychology, 30(7), 656-669. https://doi.org/10.1080/20 445911.2018.1518961

Clifford, S. (2019). How emotional frames moralize and polarize political attitudes. Political Psychology, 40(1), 75-91. https://doi.org/10.1111/ pops. 12507

Cohen, G. (2002). Deeper into bullshit. Contours of Agency: Themes from the Philosophy of Harry Frankfurt, 1, 1-9. https://doi.org/10.7551/mitpress/2143.003.0015

Druckman, J. N. (2004). Political preference formation: Competition, deliberation, and the (Ir) relevance of framing effects. American Political Science Review, 98(4), 671-686. https://doi. org/10.1017/S0003055404041413

Erat, S., \& Gneezy, U. (2012). White lies. Management Science, 58(4), 723-733. https://doi. org/10.1287/mnsc.1110.1449

Evans, A., Sleegers, W., \& Mlakar, Ž. (2020). Individual differences in receptivity to scientific bullshit. Judgment and Decision Making, 15(3), 401-412.

Fallis, D., \& Stokke, A. (2017). Bullshitting, lying, and indifference toward truth. Ergo, an Open Access Journal of Philosophy, 4(20190619). https:// doi.org/10.3998/ergo.12405314.0004.010

Frankfurt, H. G. (2005). On bullshit. Princeton University Press. https://doi.org/10.1080/10584600701641920
Hayes, A. F. (2013). Introduction to mediation, moderation, and conditional process analysis. A regression-based approach. The Guilford Press.

Jerrim, J., Parker, P., \& Shure, N. (2019). Bullshitters. Who are they and what do we know about their lives? In IZA Discussion Paper Series (No. 12282; Issue 12282).

Klaczynski, P. A. (2000). Motivated scientific reasoning biases, epistemological beliefs, and theory polarization: A two-process approach to adolescent cognition. Child Development, 71(5), 1347-1366. https://doi. org/10.1111/1467-8624.00232

Littrell, S., Risko, E. F., \& Fugelsang, J. A. (2021). The Bullshitting Frequency Scale: Development and psychometric properties. British Journal of Social Psychology, 60(1), 248-270. https://doi. org/10.1111/bjso.12379

Lodge, M., \& Taber, C. S. (2013). The rationalizing voter. Cambridge University Press.

Meibauer, J. (2016). Aspects of a theory of bullshit. Pragmatics \& Cognition, 23(1), 68-91. https:// doi.org/10.1075/pc.23.1.04mei

Moore, D. A., \& Healy, P. J. (2008). The trouble with overconfidence. Psychological Review, 115(2), 502-517. https://doi.org/10.1037/0033295X.115.2.502

Motta, M., Callaghan, T., \& Sylvester, S. (2018). Knowing less but presuming more: Dunning-Kruger effects and the endorsement of anti-vaccine policy attitudes. Social Science and Medicine, 211, 274-281. https://doi.org/10.1016/i. socscimed.2018.06.032

Newell, B. R., \& Shanks, D. R. (2014). Unconscious influences on decision making: A critical review. Behavioral and Brain Functions: BBF, 37(January), 1-61.

Ortoleva, P., \& Snowberg, E. (2015a). Overconfidence in political behavior. American Economic Review, 105(2), 504-535. https://doi. org/10.1257/aer.20130921

Ortoleva, P., \& Snowberg, E. (2015b). Are conservatives overconfident? European Journal of Political Economy, 40, 333-344. https://doi. org/10.1016/i.eipoleco.2015.04.007

Paulhus, D. L., Harms, P. D., Bruce, M. N., \& Lysy, D. C. (2003). The Over-Claiming Technique: Measuring self-enhancement independent of ability. 
Journal of Personality and Social Psychology, 84(4), 890-904. https://doi.org/10.1037/00223514.84.4.890

Pennycook, G., Cheyne, J. A. A., Barr, N., Koehler, D. J., \& Fugelsang, J. A. (2015). On the reception and detection of pseudo-profound bullshit. Judgment and Decision Making, 10(6), 549-563. https://doi.org/10.3389/fpsyg.2013.00279

Pennycook, G., \& Rand, D. G. (2019). Who falls for fake news? The roles of bullshit receptivity, overclaiming, familiarity, and analytic thinking. Journal of Personality, March, 1-16. https://doi. org/10.1111/iopy.12476

Petrocelli, J. V. (2018). Antecedents of bullshitting. Journal of Experimental Social Psychology, 76(March), 249-258. https://doi.org/10.1016/i. jesp.2018.03.004

Pfattheicher, S., \& Schindler, S. (2016). Misperceiving bullshit as profound is associated with favorable views of Cruz, Rubio, Trump and conservatism. PLOS ONE, 11(4), 1-7. https://doi. org/10.1371/journal.pone.0153419

Stanovich, K. E., \& West, R. F. (1997). Reasoning independently of prior belief and individual differences in actively open-minded thinking. Journal of Educational Psychology, 89(2), 342-357.

Stanovich, K. E., \& West, R. F. (1998). Individual differences in rational thought. Journal of Experimental Psychology, 127(2), 161-188. https:// doi.org/10.1037//0096-3445.127.2.161

Stanovich, K. E., \& West, R. F. (2007). Natural myside bias is independent of cognitive ability. Thinking \& Reasoning, 13(3), 225-247. https:// doi.org/10.1080/13546780600780796

Stanovich, K. E., \& West, R. F. (2008). On the failure of cognitive ability to predict myside and one-sided thinking biases. Thinking \& Reasoning, 14(2), 129167. https://doi.org/10.1080/13546780701679764

Tappin, B. M., \& McKay, R. T. (2019). Moral polarization and out-party hostility in the US political context. Journal of Social and Political Psychology, 7(1), 213-245. https://doi.org/10.5964/ispp. v7i1.1090

Thompson, V., \& Evans, J. S. B. T. (2012). Belief bias in informal reasoning. Thinking \& Reasoning, 18(3), 278-310. https://doi.org/10.1080/13546 783.2012 .670752

Toplak, M. E., \& Stanovich, K. E. (2003). Associations between myside bias on an informal reasoning task and amount of post-secondary education. Applied Cognitive Psychology, 17(7), 851-860. https://doi.org/10.1002/acp.915

Turpin, M. H., Walker, A. C., Kara-Yakoubian, M., Gabert, N. N., Fugelsang, J. A., \& Stolz, J. A (2019). Bullshit makes the art grow profounder. Judgment and Decision Making, 14(6), 658-670.

van Prooijen, J. W., \& Krouwel, A. P. M. (2020). Overclaiming knowledge predicts anti-establishment voting. Social Psychological and Personality Science, 11(3), 356-363. https://doi. org/10.1177/1948550619862260

Walker, A. C., Turpin, M. H., Stolz, J. A., Fugelsang, J. A., \& Koehler, D. J. (2019). Finding meaning in the clouds: Illusory pattern perception predicts receptivity to pseudo-profound bullshit. Judgment and Decision Making, 14(2), 109119. http://journal.sjdm.org/18/181212a/jdm181212a.pdf

Wilson, T. D. (2002). Strangers to ourselves. The Belknap Press of Harvard University Press. https://doi.org/10.2307/2075921 